\title{
Two new genera of Baetidae (Ephemeroptera) from Borneo (East Kalimantan, Indonesia)
}

\author{
Jean-Luc Gattolliat* \\ Museum of Zoology, Palais de Rumine, Place Riponne 6, CH-1014 Lausanne, Switzerland
}

Received 30 June 2011; Accepted 16 November 2011

\begin{abstract}
Two new genera of Baetidae are described from East Kalimantan (Borneo): Asiobaetodes n.gen. and Acerobiella n.gen. Both genera are monospecific and only known from a very restricted area. They are highly adapted to fast flow and are closely related to Oriental genera Liebebiella Waltz \& McCafferty, 1987 and Platybaetis Müller-Liebenau, 1980. Asiobaetodes is characterized by five pairs of ventrally orientated gills and tubular accessory gills at the bases of mouthparts and forelegs; these characters are also present in the Panamerican genus Baetodes Needham and Murphy, 1924 and the African genus Afrobaetodes Demoulin, 1970. The study of the mouthparts clearly indicates that the similarities must be considered as homoplasies. Acerobiella is characterised by its dorsal armature, especially the spike tubercles turned upwards on tergum II, which constitutes a unique character among the Baetidae.
\end{abstract}

Key words: Ephemeroptera / Baetidae / Asiobaetodes / Acerobiella / new genera / Borneo

\section{Introduction}

The Oriental realm presently encompasses 24 genera and about 150 species of Baetidae (Gattolliat and Nieto, 2009). A few areas such as Taiwan and Hong Kong were intensively prospected, allowing the description of several new species and genera. However, a great part of the Oriental fauna, especially in South-East Asia, remains almost unknown. Based on material collected in 1928 and 1929 during the Deutschen Limnologische Forschungreise in Java, Sumatra and Bali, Ulmer (1939) was the first to provide a comprehensive review of the Ephemeroptera from the Sunda Islands. This impressive work encompasses 79 species belonging to 11 different families collected in 123 different localities; 11 species belong to the Baetidae, seven being new to science.

For the next 40 years, almost no works were carried out in Baetidae of South-East Asia. Müller-Liebenau was the other main contributor to the knowledge of this family from this area; she published ten manuscripts describing four new genera and about 30 new species belonging to nine different genera (Müller-Liebenau, 1978, 1980a, b, 1981, 1982a, b, 1984a, b, 1985; Müller-Liebenau and Heard, 1979). A large part of her studies concerned material collected in the Gombak River in West Malaysia from where she described 16 new species (MüllerLiebenau, 1978, 1980b, 1984b). She also worked on

\footnotetext{
*Corresponding author: jean-luc.gattolliat@vd.ch
}

Baetidae from Sabah (Western part of Borneo belonging to Malaysia), discovering five new species (MüllerLiebenau, 1984a): Platybaetis probus Müller-Liebenau, 1984, Pseudocloeon borneoensis Müller-Liebenau, 1984, Baetis sabahensis Müller-Liebenau, 1984, Liebebiella proxima (Müller-Liebenau, 1984) and Chopralla pusilla (Müller-Liebenau, 1984). Since then, however, this fauna has received little attention, except for the establishment of new genera implying new generic attributions (Waltz and McCafferty, 1987a, b; McCafferty and Waltz, 1995; LugoOrtiz et al., 1999). Kluge and Novikova, (2011) just published a revision of the Acentrellini tribe (Acentrella/ fgl according to rank-free classification in Kluge and Novikova, (2011)). Besides considerations on suprageneric systematics of the Baetidae, these authors clearly defined for the first time the Acentrellini tribe. It encompasses the holoarctic genus Acentrella Bengtsson (1912), three oriental genera (Platybaetis Müller-Liebenau, 1980, Jubabaetis Müller-Liebenau, 1980 and Liebebiella Waltz and McCafferty, 1987) and one Afrotropical genus (Tanzaniops McCafferty and Barber-James, 2005). The different genera are redefined and three new species are described from Sulawesi (Liebebiella bispinosa Kluge and Novikova, 2011, Liebebiella cylindroculata Kluge and Novikova, 2011, and Platybaetis mamasae Kluge and Novikova, 2011).

The impact of logging activities on water quality and aquatic community structure was studied in Bulungan forest, Malinau District, East Kalimantan, Borneo, 
Indonesia (Derleth, 2003). The study area was limited to $85 \mathrm{~km}^{2}$, intensive prospection (34 samplings in 2000 and 2001) revealed an extremely diversified macroinvertebrate community, with 40 mayfly genera and about 50 species identified (Sartori et al., 2003). Ephemerellidae, Heptageniidae, part of the Leptophlebiidae, Prosopistomatidae and Teloganodidae were already studied in detail allowing the description of new genera and species (Sartori and Gattolliat, 2003; Jacobus and Sartori, 2004; Sartori et al., 2007, 2008; Webb and McCafferty, 2007; UberoPascal and Sartori, 2009; Sartori and Derleth, 2010). Baetidae is the most diversified family as more than 13 species were collected, part of them being not assigned to any known genus (Sartori et al., 2003). The present study constitutes the first contribution to the systematics of this family from this area; other new taxa will be described subsequently.

Holotypes and most of the paratypes of the new species are housed in the Museum of Zoology, Lausanne, Switzerland (MZL); other paratypes are deposited in the Museum of Zoology, Bogor, Indonesia (LIPI).

\section{Asiobaetodes gen.n.}

Type species. Asiobaetodes eloi Gattolliat, 2011 by present designation.

\section{Diagnostic characters}

Larva. Antennae very short, as long as head width. Head quadrangular. Mouthparts relatively short and stocky, especially maxillae and labium. Labrum short and broad (Fig. 1); right and left mandibles (Figs. 2 and 3) with canines with well-developed denticles, without tuft of setae between prostheca and mola. Maxilla (Fig. 5) stout with 2-segmented palp, shorter than galea-lacinia. Labial palp short and stocky, segment III conical with a tiny apical tip (Fig. 6). Finger-like accessory gills at the base of the mentum (Fig. 15). Legs (Fig. 8) long with abundant long and thin setae on the dorsal margin of femur and tarsus; femoral patch present; tibia longer than femur; tarsus twisted with a very long subapical seta; tarsal claw (Fig. 9) arched with 1 row of denticles. Two pairs of triangular processes on thorax (Fig. 17). Finger-like accessory gill at the base of the forelegs (Fig. 16). Five pairs of gills on segments I-V ventrally orientated (Figs. 16 and 17). Median caudal filament reduced to a few segments (Fig. 14).

Imagos. Unknown

\section{Description}

Larva

Head. Antennae (Fig. 7) very short, as long as head width, bent laterally between scape and pedicel. Labrum (Fig. 1) short and broad; distolateral arc of setae formed only by one central and a few lateral strong and very long setae. Right mandible (Fig. 2a): canine with partially fused incisors with well-developed denticles; prostheca (Fig. 2b) with small denticles apically, tuft of setae between prostheca and mola absent; distance between prostheca and mola not reduced. Left mandible (Fig. 3): canine with partially fused incisors with well-developed denticles; stout prostheca with small denticles and a comb-shaped structure apically; tuft of setae between prostheca and mola absent; distance between prostheca and mola not reduced. Lingua without patch of stout setae apically (Fig. 4). Maxilla (Fig. 5) short and stout; apically with 4 short, stout teeth, 2 multi-pointed dentisetae; 2-segmented maxillary palp stout and shorter than galea-lacinia. Labium (Fig. 6): glossae triangular, slightly shorter than paraglossae; paraglossae broad and tapered, apical margin with few long setae, stout and long subapical seta; labial palp 3-segmented, segments II and III almost fused, segment II enlarged apically but without disto-medial projection, segment III conical with a tiny apical tip. Two finger-like accessory gills at base of the mentum.

Thorax. Hindwing pads reduced to extremely minute apophysis (only visible in full mature larvae). Leg (Fig. 8) long and slender; trochanter with strong apophysis proximally; femur: dorsal margin with very long and thin setae, inner margin with only minute setae, femoral patch present; tibia clearly longer than femur, dorsal margin with 1 row of long and thin setae, ventral margin with a few minute setae; hindtibia (Fig. 10) with 1 dorsal additional row of medium stout setae (not present on other legs); tarsus twisted, short, dorsal margin almost bare, ventral margin with a few short setae and one subapical extremely developed seta; tarsal claw (Fig. 9) arched, with single row of medium size denticles; pair of subapical setae absent. Distal margin of pronotum with a pair of triangular processes; base of inner margin of forewing pads with a triangular process (Fig. 17). A fingerlike accessory gill at base of each foreleg (Fig. 16).

Abdomen. Distal margin of terga (Fig. 11) smooth with independent triangular denticles. No spines on lateral margins of terga. Five pairs of single gills on segments I-V ventrally orientated (Figs. 16-17), long and slender almost symmetrical, margin smooth without serration and setae (Fig. 12). Paraproct (Fig. 13) almost bare with smooth margin, lateral extension with a few medium size denticles. Cerci (Fig. 14) equal to body length, inner margin with very thin setae; median caudal filament (Fig. 14) reduced to a few segments.

Imagos. Unknown

\section{Discussion}

Asiobaetodes clearly belong to the Acentrellini tribe as it possesses the five characters or groups of characters used to define this tribe (Kluge and Novikova, 2011): (1) Labial palp has segment II without large inner-apical projection, segment III widened and rounded. (2) Adaptation for 

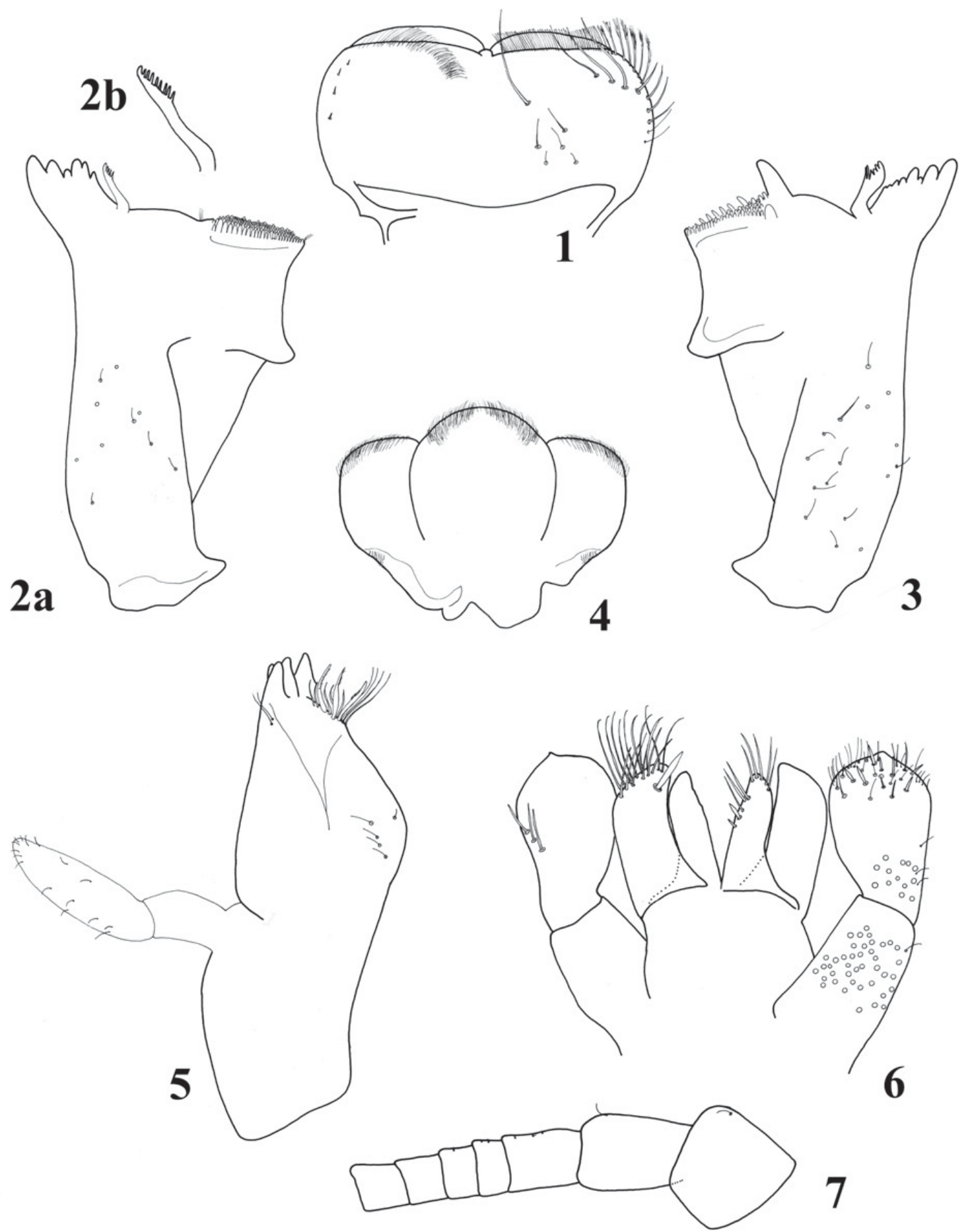

Figs. 1-7. Larval structures of Asiobaetodes eloi sp.n.: (1) labrum (left: ventral; right: dorsal). (2a) Right mandible. (2b) Right prostheca. (3) Left mandible. (4) Hypopharynx. (5) Right maxilla. (6) Labium (left: dorsal; right: ventral). (7) Antenna (scape, pedicel and first segments of flagellum).

inhabitance in rapid current (body short with ventral side flattened, peculiar shape of the head, legs widely separated and very long, tarsi twisted, cerci long with swimming setae reduced). (3) Dorsal margin of tibiae with a row of short or long setae. (4) Surface of larval abdominal terga lacks wide scales. (5) Larval paracercus is more or less reduced, never longer than $1 / 2$ of cerci.
Moreover other characters such as the short and stocky antennae (Fig. 14) arched at the level of scape and pedicel (Fig. 7), the relatively stocky mouthparts especially maxilla and labium (Figs. 5 and 6), the presence of a subapical long seta on the ventral margin of tarsus (Fig. 9), tibia clearly longer than femur (Fig. 8), the quasi absence of terminal filament (Fig. 14) clearly indicates that 

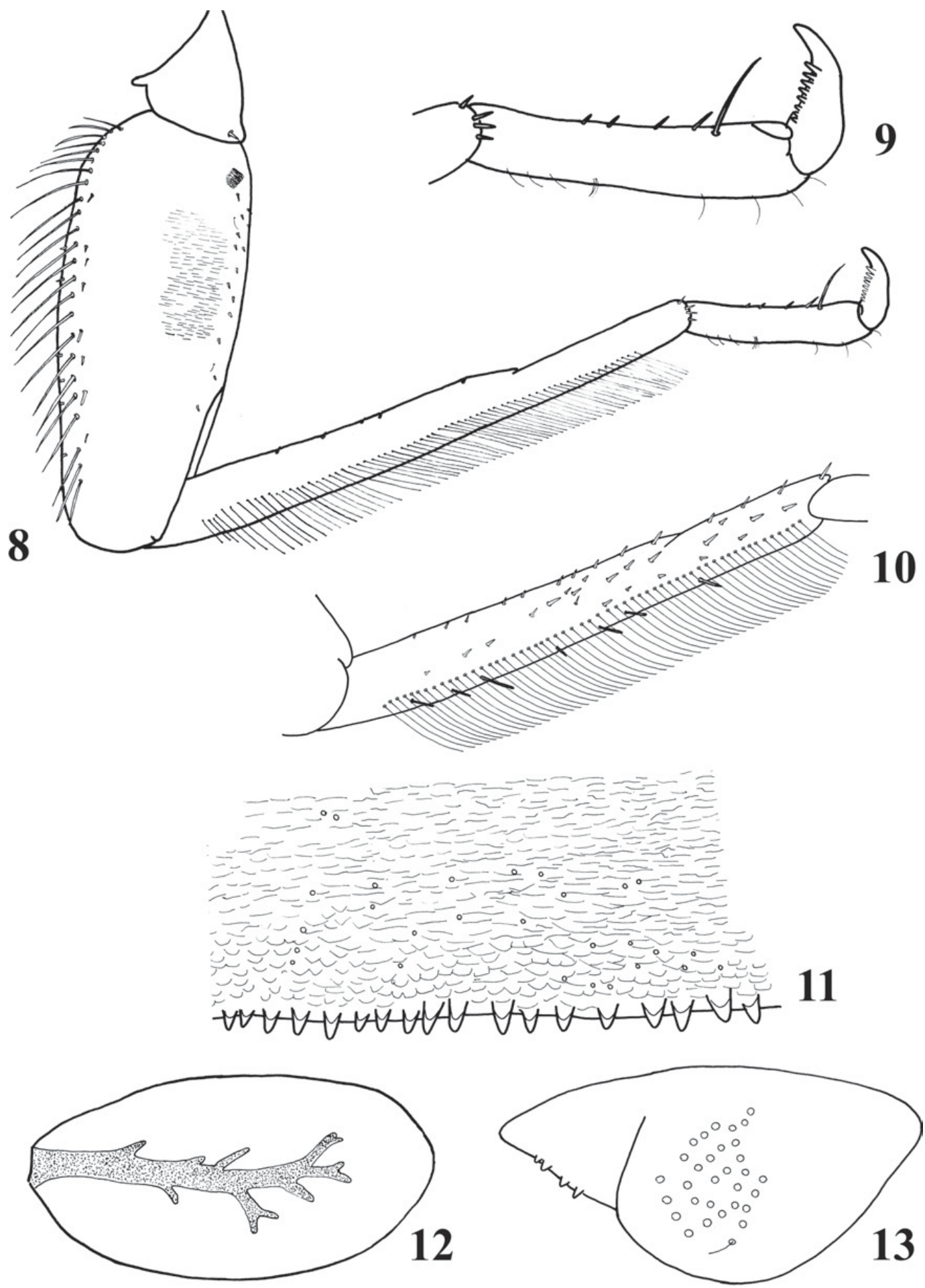

Figs. 8-13. Larval structures of Asiobaetodes eloi sp.n.: (8) Foreleg. (9) tarsal claw. (10) Hindtibia. (11) Distal margin of fourth abdominal tergum. (12) Fourth gill. (13) Paraproct.

Asiobaetodes is closely related to the genus Liebebiella. The two genera were found in the same localities and seem adapted to the same environmental factors.

Platybaetis possesses unique adaptations for crawling on the wet surfaces of rock out of the water; the structure of the legs for quickly running is unique in mayfly (Kluge and Novikova, 2011); these adaptations separate Platybaetis from Asiobaetodes and other genera of Acentrellini. Jubabaetis also has unique characters that separate it from all the other baetid genera (horizontal carina on head bordered with long setae, and shape of the mouthparts, especially of the labium 

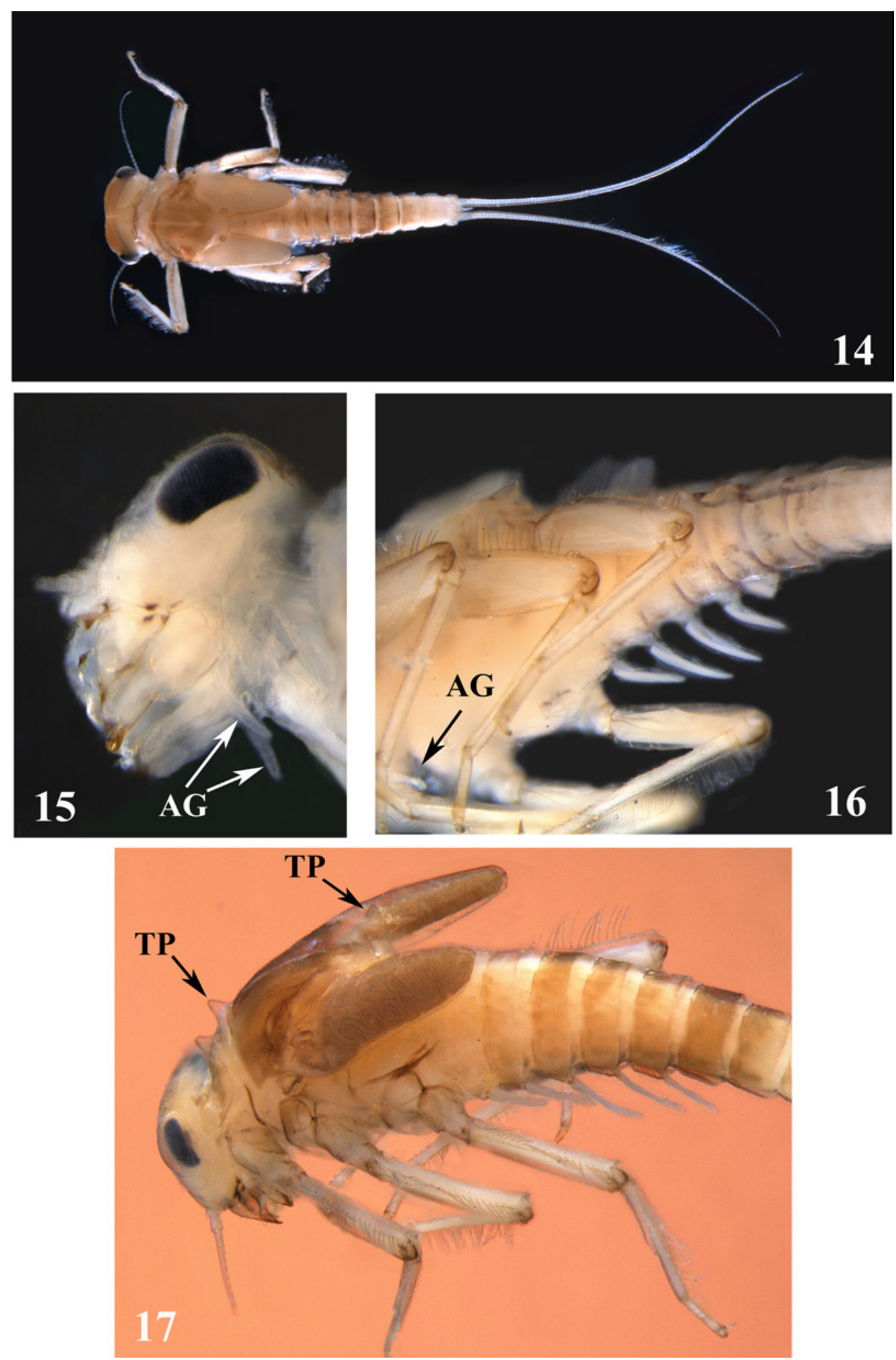

Figs. 14-17. Larval structures of Asiobaetodes eloi sp.n.: (14) Dorsal view of male larva. (15) Head (ventro-lateral view; AG = accessory gills). (16) Thorax and abdomen (ventral view; $A G=$ accessory gill). (17) Head, thorax and abdomen (dorso-lateral view; $\mathrm{TP}=$ triangular process).

and maxillae; Müller-Liebenau, 1980b). Acentrella and Tanzaniops, unlike other Acentrellini, do not possess a very long subapical seta on tibiae (Waltz and McCafferty, 1987b; Gillies, 1991a; Kluge and Novikova, 2011). Systematic position of Gratia Thomas
(1992) is not discussed in Kluge and Novikova (2011); this genus presents evident morphological similarities with the Acentrellini tribe especially with Liebebiella and Asiobaetodes (shape of the head, third segment of labial palp, short antennae bent between scape and pedicel). 
Gratia can be easily distinguished from Asiobaetodes by the absence of the very long subapical seta on tibiae, the distolateral arc of setae on labrum formed by abundant feathered setae, all terga with a single tubercle, tarsal claws with two subapical setae and dorsal margin of femora with pectinate setae (Thomas, 1992; Boonsoong et al., 2004). Baetiella Ueno, 1931 is superficially similar to Acentrellini; this genus was, however, included in the Baetini tribe (Baetosterna or Baetis/fg9 according to Kluge and Novikova, 2011). Baetiella is not dorsoventrally flattened; it possesses elongated symmetrical labial palp and tarsi which do not bear a long subapical seta (Braasch, 1983; Waltz and McCafferty, 1987b; Tong and Dudgeon, 2000).

Asiobaetodes can be easily separated from other Acentrellini and from all the presently known Asian genera of Baetidae by the presence of ventrally orientated gills and finger-like accessory gills at the base of mouthparts and forelegs. This combination of characters is only known in genera of Panamerican Baetodes complex (Lugo-Ortiz and McCafferty, 1996), and the Afrotropical genera Afrobaetodes Demoulin, 1970 (Gillies, 1991b; Gattolliat and Sartori, 1999) and Thraulobaetodes Elouard and Hideux, 1991. Asiobaetodes differs from Baetodes and related genera by the shape of the labium, especially of the labial palp, the shape and setation of the labrum, the setation of the dorsal margin of femora and the tarsal claw with a subapical seta in lateral margin (Dominguez et al., 2006). Afrobaetodes and Thraulobaetodes can be separated from Asiobaetodes by right and left mandibles with or without tuft of setae between prostheca and mola, the number of sets of incisors of the right mandible, the shape of the labial palp, the shape and setation of the glossae and paraglossae, the tarsal claws with single or double rows of denticles and shape and setation of the legs (Elouard and Hideux, 1991; Gattolliat and Sartori, 1999). Consequently, the examination of these characters clearly indicates that the genera of the different biogeographic realms belong to different lineages. Additional gills mainly located between coxae and sterna, or sometimes between coxae and trochanters are present in different unrelated genera which give evidence for parallel evolution of this character in various lineages (for a complete review of the Baetidae genera with additional gills refer to Staniczek, 2010; Zhou, 2010).

The two paired triangular processes on the thorax (Fig. 17) without additional processes on the abdomen are also singular in Baetidae.

\section{Etymology}

Asiobaetodes is a combination of Asio - in reference to the geographic area where the genus was found and baetodes to highlight the superficial similarities with the Panamerican genus Baetodes Needham and Murphy, 1924. The gender is masculine.

\section{Asiobaetodes eloi sp.n.}

\section{Type material}

\section{Holotype}

One male larva; B0521; Indonésie; Est Kalimantan; Loc. Seturan (2001-bloc 57); Riv. Tamalang (affluent du Seturan); 259'50"N/116³0'29"E; 19.07.2000; Coll. Derleth Pascale and Beboux François.

\section{Paratypes}

Four male larvae, 9 female larvae; same data as holotype.

One female larva; B0410; Indonésie; Est Kalimantan; Loc. Langap Sud (1995); Riv. Ngayo (affluent de Rian); $3^{\circ} 04^{\prime} 41 " \mathrm{~N} / 116^{\circ} 31^{\prime} 11^{\prime \prime E}$; Alt. $160 \mathrm{~m}$; 14.06.2000; Coll. Derleth Pascale.

One male larva, 2 female larvae, 5 larvae; B0511A; same locality as holotype; 18.07.2000; Coll. Derleth Pascale and Beboux François.

Two male larvae, 5 female larvae (1 larva on slide), 1 larva; B0411; same locality as holotype; 08.07.2000; Coll. Derleth Pascale.

One female larva; B0421; Indonésie; Est Kalimantan; Loc. Langap Sud (1995); Riv. Ngayo (affluent de Rian); $3^{\circ} 04^{\prime} 41 " N / 116^{\circ} 31^{\prime} 15^{\prime \prime E}$; Alt. 160 m.; 12.07.2000; Coll. Derleth Pascale.

One larva; B0431; Indonésie; Est Kalimantan; Loc. Seturan camp; Riv. Ngayo (affluent de Rian); $3^{\circ} 00^{\prime} 20^{\prime \prime N} / 116^{\circ} 30^{\prime} 36 " E ;$; 13.07.2000; Coll. Derleth Pascale.

One female larva; B0433; Indonésie; Est Kalimantan; Loc. Langap Sud (1995); Riv. Ngayo (affluent de Rian); $3^{\circ} 04^{\prime} 56 " \mathrm{~N} / 116^{\circ} 30^{\prime} 58^{\prime \prime E}$; Alt. 160 m.; 14.04.2001; Coll. Derleth Pascale and Sartori Michel.

One male larva, 3 female larvae; B0513; Indonésie; Est Kalimantan; Loc. Seturan (2001-bloc 57); Riv. Tamalang (affluent du Seturan); 2 59'22"N/116 30'29"E; 10.04.2001; Coll. Derleth Pascale.

Three male larvae, 4 female larvae, 9 larvae; B0531; Indonésie; Est Kalimantan; Loc. Seturan (2001-bloc 57); Riv. Tamalang (affluent du Seturan); $2^{\circ} 59^{\prime} 22^{\prime \prime N} /$ 116 30'46"E; 8.08.2000; Coll. Derleth Pascale.

One male larva, 2 female larvae, 2 larvae (1 larva on slide); B0541; same locality; 19.08.2000; Coll. Derleth Pascale and Schlaepfer Rodolphe.

Three female larvae; B0533; same locality; 11.04.2001; Coll. Derleth Pascale and Feldmeyer Barbara.

One male larva, 1 female larva; B0631; Indonésie; Est Kalimantan; Loc. Seturan (2000-bloc 45); Riv. Wok (Sungai Guang) (affluent du Seturan); 2 59'11"N/ 116 33'30"E; 29.06.2000; Coll. Derleth Pascale.

Four male larvae, 5 female larvae, 1 larva; B0713; Indonésie; Est Kalimantan; Loc. Seturan (2000-bloc 44-45); Riv. Wok (Sungai Guang) (affluent du Seturan); 2॰59'12"N/116 33'11"E; 5.04.2001; Coll. Derleth Pascale and Feldmeyer Barbara. 
One larva; B0811; Indonésie; Est Kalimantan; Loc. Seturan (2000-bloc 43); Riv. Temalat (Sungai Guang) (affluent du Seturan); 2 59'29"N/116 33'29"E; 18.06.2000; Coll. Derleth Pascale and Gattolliat Jean-Luc.

Two female larvae; B0812; same locality; 16.08.2000; Coll. Derleth Pascale and Schlaepfer Rodolphe.

Two male larvae; B0813; same locality; 2.04.2001; Coll. Derleth Pascale.

One male larva, 1 female larva, 1 larva; B1211; Indonésie; Est Kalimantan; Loc. Langap Sud (1999-bloc 24); Riv. Rian; $3^{\circ} 01^{\prime} 40^{\prime \prime} \mathrm{N} / 116^{\circ} 31^{\prime} 05^{\prime \prime E}$; 11.07.2000; Coll. Derleth Pascale.

One male larva; B1313; Indonésie; Est Kalimantan; Loc. Seturan (non exploité); Riv.; $3^{\circ} 00^{\prime} 05^{\prime \prime N} / 116^{\circ} 30^{\prime} 48^{\prime \prime} E$; 28.03.2001; Coll. Derleth Pascale and Barbara Feldmeyer.

\section{Description}

Larva

Length. Male: body length 2.5-3.2 mm; cerci $3.5-4.2 \mathrm{~mm}$. Female: body length $3.0-4.0 \mathrm{~mm}$; cerci $4.0-4.5 \mathrm{~mm}$.

Color (online, Figs. 14 and 17). Head uniformly medium amber brown, without vermiform marking on vertex and frons; antennae yellow cream; turbinate eyes light honey brown. Thorax brown without clear pattern. Legs yellow cream except apex of femora darker. Terga IVII brown generally with an interrupted dark brown band distally; terga VIII-X yellow. Sterna I-VII brown; sterna VIII and IX yellow. Cerci and median caudal filament uniformly yellow without darker stripe.

Head. Antennae (Fig. 7) almost bare, margin not crenulated. Dorsal surface of the labrum (Fig. 1) with one central and 4 disto-lateral long setae; distal margin bordered with simple setae, disto-lateral setae feathered; ventral surface with 4 minute pointed setae apico-laterally. Hypopharynx (Fig. 4), lingua apically rounded covered with minute setae distally; superlingua shorter than lingua, distally with thin setae. Right mandible (Fig. 2a) with two sets of incisors both with 3 denticles; basal half with a few thin setae dorsally. Left mandible (Fig. 3) with two sets of incisors with 5 and 3 denticles, respectively; basal half with a few thin setae dorsally. Maxilla (Fig. 5): apically with 1 row of a few stout setae slightly pectinate, half length of teeth, long and stout setae distally; maxillary palp segment I less than half length of segment II. Labium (Fig. 6); margin of glossae with a few medium stout simple setae, lateral surfaces bare; paraglossae subrectangular; distal margin with 1 row of long simple setae and 1 row of medium simple setae, a single very stout seta distolaterally; labial palp segment I almost bare, subequal in length to segments II and III combined; segments II and III almost fused, segment II almost bare ventrally and laterally, dorsally with 1 longitudinal row of 3 stout setae; segment III much broader than long, with scattered thin setae and stout setae.
Thorax. Foreleg (Fig. 8), trochanter bare except for a short stout seta distally. Femur: dorsal margin with 1 row of about 20 long thin setae and 1 additional row of tiny stout setae closer to margin, with 1 row of small setae subparallel to dorsal margin; dorso-apical setal patch absent; lateral faces partially shagreened; ventral margin with short pointed setae. Apex of tibia with 4 small pointed setae; dorsal margin of hindtibia (Fig. 10) with an additional row of about 6 medium stout setae. Dorsal margin of tarsus with only few very thin setae; ventral margin with 1 row of about 4 small setae and apical seta only slightly shorter than tarsal claw; tarsal claw (Fig. 9) about $0.4 \times$ length of tarsus, with 1 row of 8 denticles in sublateral position.

Abdomen. Terga (Fig. 11) shagreened, with traces of insertion of setae, without scale bases. Gills (Fig. 12) with tracheation well marked but poorly divided. Paraproct (Fig. 13) without scale bases; lateral extension bare without scale bases, margin with 4 denticles. Cerci (Fig. 14) with numerous extremely thin setae on inner margin. Median caudal filament subequal to tergum $\mathrm{X}$ (Fig. 14).

\section{Etymology}

This species is dedicated to my godson Eloi Braillard.

\section{Distribution and habitat}

Asiobaetodes eloi is relatively widespread in the prospected area, and was found in about half of the localities. This species is never abundant, however, as only one to four larvae were collected per sample. Larvae inhabit small to medium streams (up to $10 \mathrm{~m}$ wide), $0.1-$ $0.8 \mathrm{~m}$ depth and with medium to fast flow $(0.5-1.4 \mathrm{~m} / \mathrm{s}$, but generally between 0.8 and $0.9 \mathrm{~m} / \mathrm{s}$ ). This species was mainly found in unlogged or recently logged lowland Dipterocarpacae forest. It was mostly absent from stream for 1-3 years following logging, but reappeared 4-5 years after logging when the water quality seems to have recovered (Derleth, 2003). The habitat of Asiobaetodes eloi seems wide; in each locality, the species was found in most of the samples representing different habitats.

\section{Acerobiella gen.n.}

Type species: Acerobiella alinae Gattolliat, 2011 by present designation.

\section{Diagnostic characters}

Larva. Antennae (Fig. 24) very short, as long as head width. Head quadrangular. Mouthparts short and stocky. Labrum (Fig. 18) short and broad; right and left mandibles short and slender (Figs. 19-20), almost as 

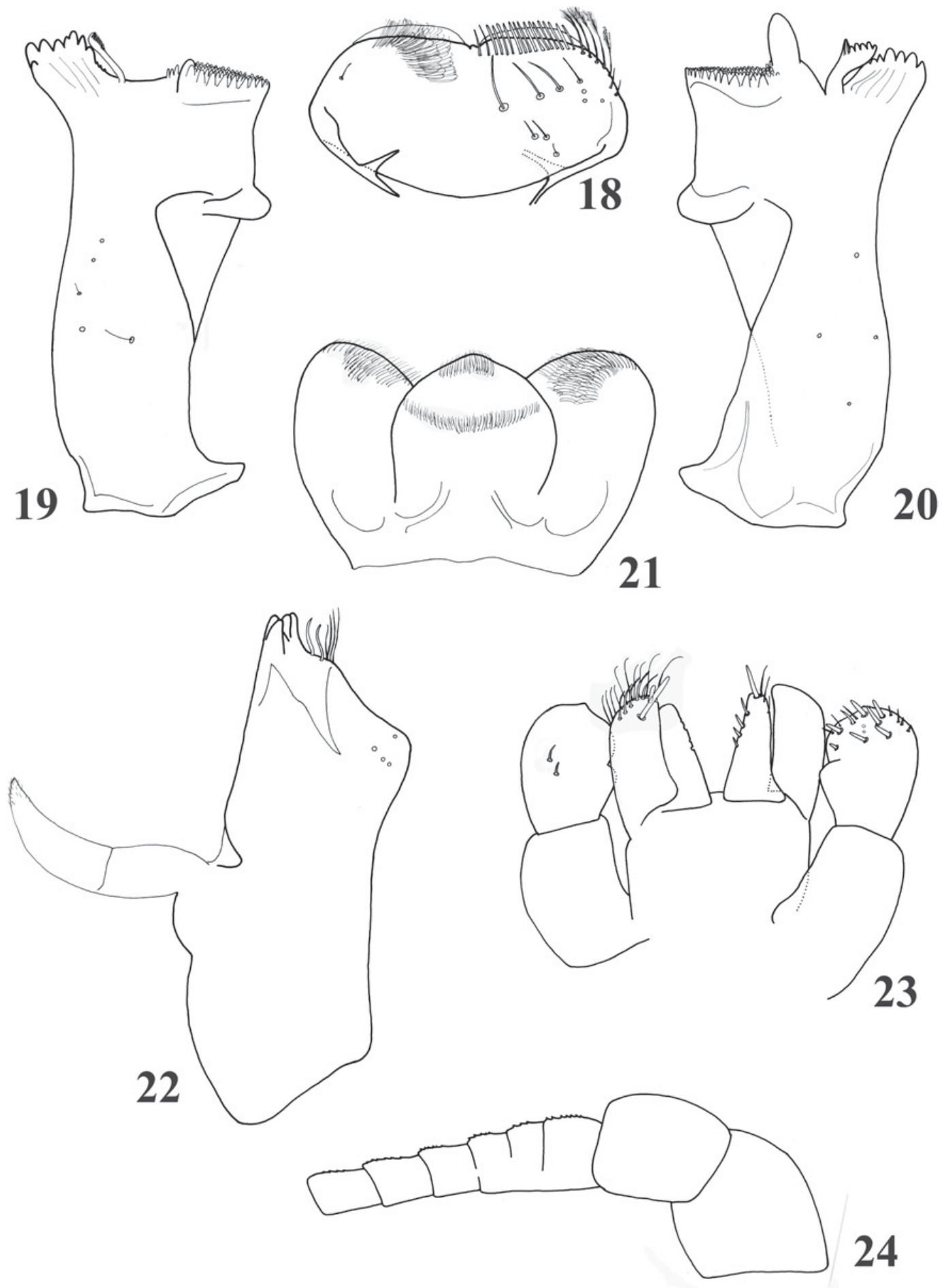

Figs. 18-24. Larval structures of Acerobiella alinae sp.n.: (18) Labrum (left: ventral; right: dorsal). (19) Right mandible, ventral. (20) Left mandible. (21) hypopharynx. (22) Right maxilla. (23) Labium (left: dorsal; right: ventral). (24) Antenna (scape, pedicel and first segments of flagellum).

broad proximally than distally; distance between prostheca and mola was reduced, without tuft of setae. Maxilla (Fig. 22) stout with 2-segmented palp, shorter than galealacinia. Glossae and paraglossae (Fig. 23) short with a strong spine-like seta distally; labial palp short and stocky, segment III conical with a tiny apical tip. Legs (Fig. 25) elongated with abundant long and thin setae on the dorsal margin of femur and tarsus; femoral patch reduced; tibia longer than femur; tarsus twisted with a very long subapical seta; tarsal claw (Fig. 26) arched with a single row of denticles. Tergum II (Fig. 31) with two spike-like tubercles turned toward the head; terga I, III to V (Fig. 27) 

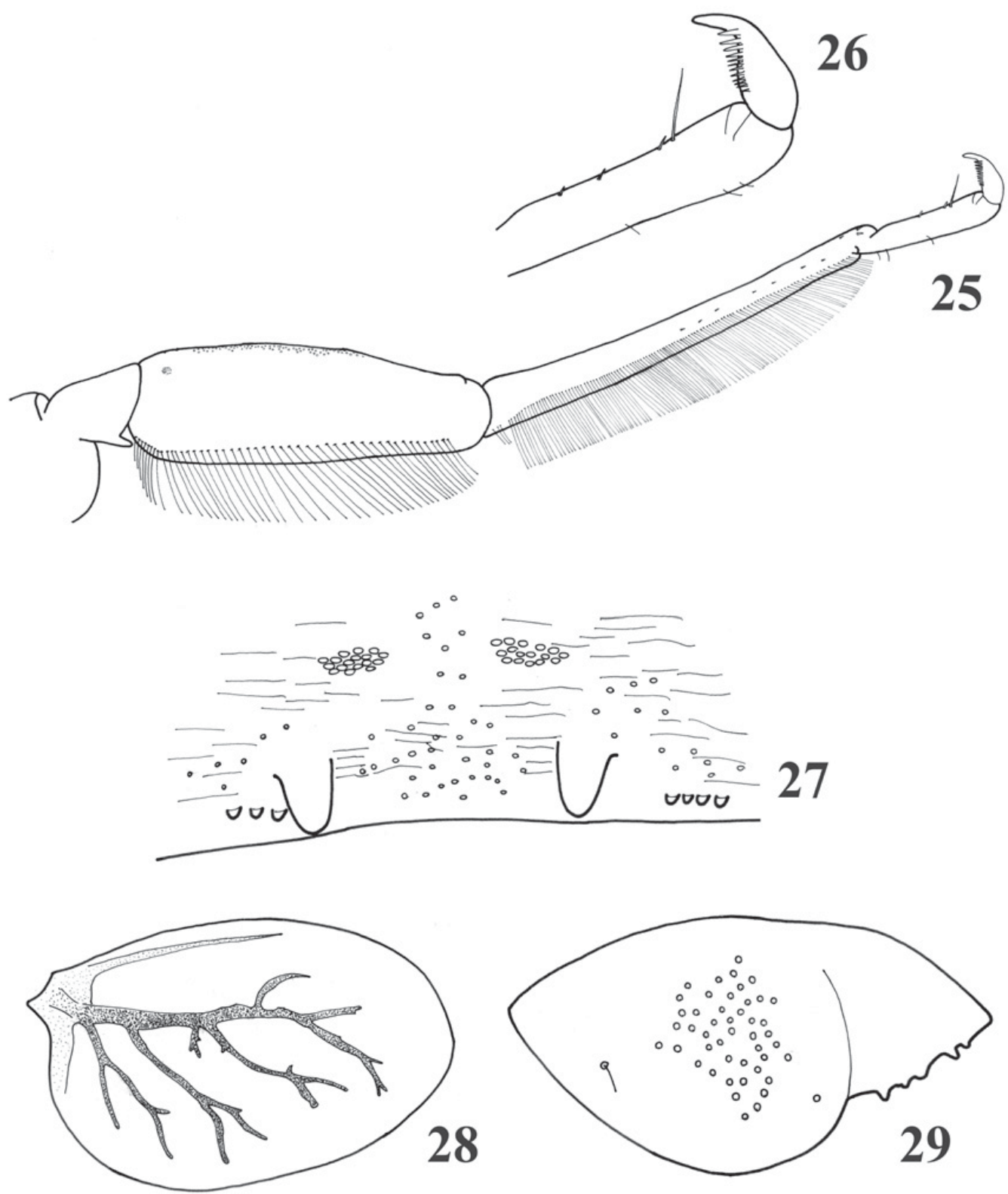

Figs. 25-29. Larval structures of Acerobiella alinae sp.n. (25) Foreleg. (26) Tarsal claw. (27) Distal margin of fourth abdominal tergum. (28) Fourth gill. (29) Paraproct.

with small rounded paired tubercles. Seven pairs of gills laterally orientated. Median caudal filament reduced to a few segments.

Imagos. Unknown.

\section{Description}

\section{Larva}

Head. Antennae (Fig. 24) very short, as long as head width, bent laterally between scape and pedicel. Head quadrangular. Labrum (Fig. 18) short and broad; distolateral arc of setae composed of one central and a few lateral medium setae, clearly distant from distal margin.
Right mandible (Fig. 19): canine with almost completely fused incisors with well-developed denticles; prostheca with small denticles apically, tuft of setae between prostheca and mola absent; distance between prostheca and mola reduced; mola well-developed with numerous small denticles. Left mandible (Fig. 20): canine with almost completely fused incisors with well-developed denticles; stout prostheca with small denticles and combshaped structure apically; tuft of setae between prostheca and mola absent; margin between prostheca and mola was reduced and oriented at $45^{\circ}$; thumb of mola extremely developed, longer than incisors. Lingua without patch of stout setae apically (Fig. 21). Maxilla (Fig. 22) short and stout: apically with 4 short and stout teeth, two simple dentisetae; 2-segmented maxillary palp, stout and shorter 
than galea-lacinia. Labium (Fig. 23): glossae triangular, slightly shorter than paraglossae, with a strong spine-like seta apically; paraglossae broad and tapered, apical margin with a few long setae, stout and long subapical spine-like seta; labial palp 3-segmented, segment II and III almost fused, segment II short and broad, enlarged apically but with reduced disto-medial projection, segment III conical with a tiny apical tip and stout short spine-like setae. Accessory gills absent.

Thorax. Hindwing pads reduced to minute process. Leg (Fig. 25) long and slender; trochanter with strong apophysis distally; dorsal margin of femur with very long and thin setae, inner margin with only minute setae, femoral patch present but reduced; tibia clearly longer than femur, dorsal margin with one row of long and thin setae, ventral margin almost bare; tarsus twisted, short, dorsal margin almost bare, ventral margin with a few short setae and one subapical extremely developed seta; tarsal claw (Fig. 26) strongly arched with single row of medium size denticles; pair of subapical setae absent. Thorax without processes or apophysis dorsally. Accessory gills absent.

Abdomen. Distal margin of terga (Fig. 27) smooth with a restricted number of independent triangular denticles parallel to margin. Tergum I with two strong triangular tubercles; tergum II with two spike-like tubercles turned toward the head (Fig. 31); terga III-V with small rounded paired tubercles (Fig. 31); extremely thin and long setae perpendicular to surface mainly abundant between tubercles. No spines on lateral margins of terga. Seven pairs of single gills (Fig. 28), laterally orientated, asymmetrical, well tracheated, margin smooth without serration and setae. Paraproct (Fig. 29) almost bare with smooth margin, lateral extension with a few medium denticles. Cerci slightly shorter than body length, inner margin with very thin setae; median caudal filament reduced to a few segments.

Imagos. Unknown.

\section{Discussion}

Acerobiella is assigned to the Acentrellini tribe as it also possesses the five characters of this tribe cited above (Kluge and Novikova, 2011). It presents obviously strong affinities with the new genera Asiobaetodes and Liebebiella. Legs of Acerobiella (Fig. 25) and Asiobaetodes (Fig. 8) are very similar. The mouthparts, especially the mandibles (Figs. 19-20) and maxillae (Fig. 22) of Acerobiella and of some species of Liebebiella, are also similar. Acerobiella can be easily distinguished from Asiobaetodes by the number and orientation of the abdominal gills, the absence of accessory gills, the shape, the number and the position of the tubercles on thorax and abdomen. Besides the presence of tubercles, Acerobiella can be separated from Liebebiella by the claws without a pair of subapical setae (Fig. 26), the femora and tibia (Fig. 25) with simple long setae on the dorsal margin (multilaterally ciliate setae in Liebebiella) and the general body shape (not flattened in
Liebebiella) (Waltz and McCafferty, 1987b). The different characters listed to distinguish Asiobaetodes from Acentrella, Gratia, Jubabaetis, Platybaetis and Tanzaniops can be also used to separate Acerobiella from these five genera.

The presence on tergum II of two forwardly projecting spike-like tubercles (Fig. 31) is a unique character that distinguishes Acerobiella from any other genus of Baetidae or even Ephemeroptera; in all the known genera with tubercles on the abdomen, these tubercles are always rearwardly orientated.

\section{Etymology}

The name is a combination of the adjective acer meaning pointed, thorny in allusion to the two spike-like tubercules on the abdomen and - biella based on the family name of Ingrid Müller-Liebenau in recognition of her important work and in reference to the closely related genus Liebebiella. The gender is feminine.

\section{Acerobiella alinae sp.n.}

\section{Type material}

\section{Holotype}

One female larva; B0521; Indonésie; Est Kalimantan; Loc. Seturan (2001-bloc 57); Riv. Tamalang (affluent du Seturan); $\quad 2^{\circ} 59^{\prime} 50^{\prime \prime N} / 116^{\circ} 30^{\prime 2} 29^{\prime \prime E} ; \quad 19.07 .2000 ; \quad$ Coll. Derleth Pascale and Beboux François.

\section{Paratypes}

Three male larvae, 4 female larvae, 1 larva (1 larva on slide); same data as holotype.

Six larvae; B0521; same locality as holotype; 19.07.2000; Coll. Derleth Pascale and Beboux François.

Six male larvae, 9 female larvae, 7 larvae; B0513; Indonésie; Est Kalimantan; Loc. Seturan (2001-bloc 57); Riv. Tamalang (affluent du Seturan); $2^{\circ} 59^{\prime} 22^{\prime \prime N} /$ 116 30'29"E; 10.04.2001; Coll. Derleth Pascale.

Three female larvae; B0533; Indonésie; Est Kalimantan; Loc. Seturan (2001-bloc 57); Riv. Tamalang (affluent du Seturan); 2 59'22"N/116 30'46"E; 11.04.2000; Coll. Derleth Pascale and Feldmeyer Barbara.

One male larva; B0541; same locality; 19.08.2000; Coll. Derleth Pascale and Schlaepfer Rodolphe.

\section{Description}

\section{Larva}

Length. Male: body length 3.3-3.6 mm; cerci 2.1-2.3 $\mathrm{mm}$. Female: body length $3.7-3.9 \mathrm{~mm}$; cerci $2.2-2.3 \mathrm{~mm}$. 

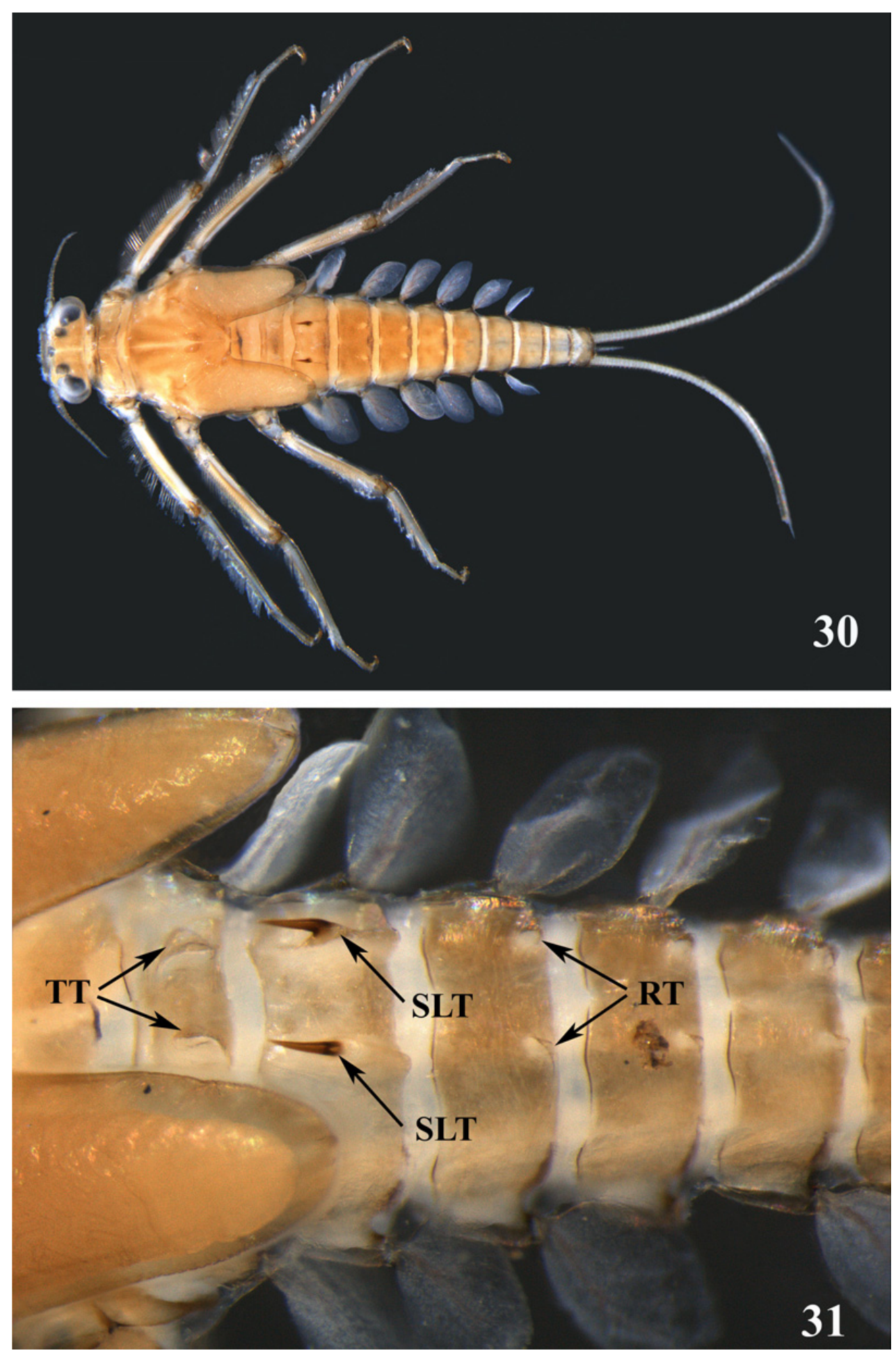

Figs. 30-31. Larval structures of Acerobiella alinae sp.n. (30) Dorsal view of female larva. (31) Abdomen (dorso-lateral view; $\mathrm{TT}=$ triangular tubercles; $\mathrm{SLT}=$ spike-like tubercles; $\mathrm{RT}=$ rounded tubercles).

Color (online, Figs. 30 and 31). Head uniformly medium amber brown, without vermiform marking on vertex and frons; antennae yellow cream; turbinate eyes honey brown. Thorax brown without clear pattern. Legs yellow cream except apex of femora darker. Terga I-VI medium brown with a brown band distally; tubercles on terga I and III-V yellow, tubercles on tergum II dark brown; terga VII-IX light brown with a symmetrical medium brown dot and a brown longitudinal stripe in middle of tergum. Sterna yellow. Cerci and median caudal filament uniformly yellow without darker stripe.

Head. Antennae (Fig. 24) bare, margin of pedicel crenulated. Dorsal surface of labrum (Fig. 18) with 1 central and 3 disto-lateral medium setae; distal margin 
bordered with a row simple stout setae, disto-lateral setae longer and feathered; ventral surface with a minute pointed seta apico-laterally. Right mandible (Fig. 19), incisors with 7 denticles, outer denticle clearly shorter, inner margin crenated. Left mandible (Fig. 20), incisors with 7 denticles. Hypopharynx (Fig. 21), lingua apically triangular covered only with minute setae; superlingua slightly longer than lingua, apically with thin setae. Maxilla (Fig. 22) apically with 1 row of setae reduced to 2 dentisetae and 4 medium setae distally; maxillary palp segment I less than 0.7 length of segment II; segment II progressively narrower toward apex, with small thin setae apically. Labium (Fig. 23), inner margin of glossae with a few short to medium stout setae, a stout long seta subapically, a few thin setae apically, lateral surfaces bare; paraglossae subrectangular; distal margin with 3 rows of long simple setae, single very stout seta distolaterally longer than all other setae; lateral margins bare; labial palp segments I and II almost bare, segment I stout and broad, slightly longer than segments II and III combined; segment II dorsally with 1 longitudinal row of 2 stout setae; segment III much broader than long, with scattered stout short setae and a few thin short setae.

Thorax. Forelegs (Fig. 25), trochanter bare. Femur: dorsal margin with 1 row of about 45 long thin setae, without additional row of setae; dorso-apical setal patch absent; lateral faces not shagreened; ventral margin with minute setae. Tibia with only a few scattered setae, except for 1 dorsal row of thin setae. Dorsal margin of tarsus almost bare; ventral margin with 1 row of 3 small setae and apical seta only slightly shorter than tarsal claw; tarsal claw (Fig. 26) about $0.4 \times$ length of tarsi, with 1 row of about 11 denticles in sublateral position.

Abdomen. Terga (Fig. 27) slightly shagreened, with traces of insertion of setae, without scales or scale bases, distal margin smooth; groups of 3-5 independent spines parallel to distal margin. Gills (Fig. 28) with divided and well-marked tracheation. Paraproct (Fig. 29) almost bare and without scale bases; lateral extension bare without scale bases, margin with 4-5 poorly developed denticles. Cerci (Fig. 30) with numerous extremely thin setae on inner margin. Median caudal filament (Fig. 30) slightly longer than tergum $\mathrm{X}$.

\section{Etymology}

This species is dedicated to Aline Pasche.

\section{Distribution and habitat}

A. alinae is only known from four different localities of the same stream; it was always collected with Asiobaetodes eloi. A. alinae is clearly less widespread than Asiobaetodes eloi but can be locally abundant. It was collected in a stream $10 \mathrm{~m}$ wide, $0.4-0.6 \mathrm{~m}$ deep and relatively fast flow $(0.8-0.9 \mathrm{~m} / \mathrm{s})$. All the localities are in primary and secondary mixed forest, 6 months after logging activities (Derleth, 2003).

Acknowledgements. I am deeply indebted to Pascale Derleth Sartori (SESA, Lausanne, Switzerland) who collected the material studied. Fruitful discussions by Luke Jacobus (Indiana University, Bloomington, USA) helped to improve the manuscript. I want to thank Helen Barber-James (Albany Museum, Grahamstown, South Africa); Carolina Nieto (CONICETINSUE. Fac. de Cs. Naturales e I.M.L. Tucumán, Argentina); Michel Sartori (Museum of Zoology, Lausanne, Switzerland) and Jeff Webb (Biodiversity Institute of Ontario, University of Guelph, Ontario Canada) for their useful comments on the draft.

\section{References}

Boonsoong B., Thomas A. and Sangpradub N., 2004. Gratia narumonae n. sp., a new mayfly from Thailand (Ephemeroptera, Baetidae). Ephemera, 4, 1-9.

Braasch D., 1983. Neue Baetidae von Nepal (Ephemeroptera). Rechenbachia Mus. Terkd. Dresden, 21, 96-155.

Derleth P., 2003. Benthic macroinvertebrates and logging activities: a case study in a lowland tropical forest in East Kalimantan (Indonesian Borneo). School of Architecture, Civil and Environmental Engineering, Swiss Federal Institute of Technology, Lausanne, $174 \mathrm{p}$.

Domínguez E., Molineri C., Pescador M.L., Hubbard M.D. and Nieto C., 2006. Ephemeroptera of South America. In: Aquatic Biodiversity in Latin America, Vol. 2, Pensoft Press, Sofia and Moscow, $650 \mathrm{p}$.

Elouard J.-M. and Hideux P., 1991. Mayflies of West Africa. Thraulobaetodes, an atypical new genus of crawling Baetidae. In: Alba-Tercedor J. and Sanchez-Ortega A. (eds.), Overviews and Strategies of the Ephemeroptera and Plecoptera, Sandhill Crane Press Inc., Gainesville, 169-174.

Gattolliat J.-L. and Nieto C., 2009. The family Baetidae (Insecta: Ephemeroptera): synthesis and future challenges. Aquat. Insects, 31, 41-62.

Gattolliat J.-L. and Sartori M., 1999. A new species of Afrobaetodes (Ephemeroptera, Baetidae) and first report of this genus from Madagascar. Ann. Limnol. - Int. J. Lim., 35, 179-184.

Gillies M.T., 1991a. A diphyletic origin for the two-tailed baetid nymphs occurring in East African stony streams with a description of the new genus and species Tanzaniella spinosa gen. sp. nov. In: Alba-Tercedor J. and SanchezOrtega A. (eds.), Overviews and Strategies of the Ephemeroptera and Plecoptera, Sandhill Crane Press Inc., Gainesville, 175-187.

Gillies M.T., 1991b. New records and a new species of Afrobaetodes Demoulin (Baetidae, Ephemeroptera) from Tanzania. Rev. Hydrobiol. Trop., 24, 105-110.

Jacobus L.M. and Sartori M., 2004. Review of the genus Hyrtanella (Ephemeroptera: Ephemerellidae). Zootaxa, 785, $1-12$.

Kluge N.J. and Novikova E.A., 2011. Systematics of the mayfly taxon Acentrella (Ephemeroptera: Baetidae), with description of new Asian and African species. Russian Entomol. J., $20,1-56$. 
Lugo-Ortiz C.R. and McCafferty W.P., 1996. Phylogeny and classification of the Baetodes complex (Ephemeroptera: Baetidae), with description of a new genus. J. N. Am. Benthol. Soc., 15, 367-380.

Lugo-Ortiz C.R., McCafferty W.P. and Waltz R.D., 1999. Definition and reorganization of the genus Pseudocloeon (Ephemeroptera: Baetidae) with new species descriptions and combinations. Trans. Am. Entomol. Soc., 125, 1-37.

McCafferty W.P. and Waltz R.D., 1995. Labiobaetis (Ephemeroptera: Baetidae): new status, new North American species, and related new genus. Entomol. News, 106, 19-28.

Müller-Liebenau I., 1978. Raptobaetopus, eine neue carnivore Ephemeropteren-Gattung aus Malaysia (Insecta, Ephemeroptera: Baetidae). Arch. Hydrobiol., 82, 465-481.

Müller-Liebenau I., 1980a. Jubabaetis gen. n. and Platybaetis gen. n., two new genera of the family Baetidae from the oriental region. In: Flannagan J.F. and Marshall K.E. (eds.), Advances in Ephemeroptera Biology, Plenum Press, New York, 103-114.

Müller-Liebenau I., 1980b. A new species of the genus Platybaetis Müller-Liebenau 1980, P. bishopi sp.n. from Malaysia (Insecta, Ephemeroptera). Gewäss. Abwäss., 66/67, 95-101.

Müller-Liebenau I., 1981. Review of the original material of the baetid genera Baetis and Pseudocloeon from the Sunda Islands and the Philippines described by G. Ulmer, with some general remarks (Insecta: Ephemeroptera). Mitt. Hamb. Zoo. Mus. Inst., 78, 197-208.

Müller-Liebenau I., 1982a. Five new species of Pseudocloeon Klapalek, 1905, (Fam. Baetidae) from the Oriental region (Insecta, Ephemeroptera) with some general remarks on Pseudocloeon. Arch. Hydrobiol., 95, 283-298.

Müller-Liebenau I., 1982b. New species of the family Baetidae from the Philippines (Insecta, Ephemeroptera). Arch. Hydrobiol., 94, 70-82.

Müller-Liebenau I., 1984a. Baetidae from Sabah (East Malaysia) (Ephemeroptera). In: Landa V., Soldán T. and Tonner M. (eds.), Proceeding of the Fourth International Conference on Ephemeroptera, CSAV, Bechyne, 85-99.

Müller-Liebenau I., 1984b. New genera and species of the family Baetidae from West-Malaysia (River Gombak) (Insecta: Ephemeroptera). Spixiana, 7, 253-284.

Müller-Liebenau I., 1985. Baetidae from Taiwan with remarks on Baetiella Ueno, 1931 (Insecta, Ephemeroptera). Arch. Hydrobiol., 104, 93-110.

Müller-Liebenau I. and Heard W.H., 1979. Symbiocloeon: a new genus of Baetidae from Thailand (Insecta: Ephemeroptera). In: Pasternak K. and Sowa R. (eds.), Proceedings of the
Second International Conference on Ephemeroptera, Panstwowe Wydawnictwo Naukowe, Warszawa, 57-66.

Sartori M. and Derleth P., 2010. The dipterous Leptophlebiidae of Borneo (Insecta, Ephemeroptera). Zootaxa, 2490, 33-39.

Sartori M. and Gattolliat J.L., 2003. First record and new species of the genus Prosopistoma Latreille, 1833 (Ephemeroptera, Prosopistomatidae) from Borneo (East Kalimantan, Indonesia). Mitt. Schweiz. Entomol. Ges., 76, 301-305.

Sartori M., Derleth P. and Gattolliat J.L., 2003. New data about the mayflies (Ephemeroptera) from Borneo. In: Gaino E. (ed.), Research Update on Ephemeroptera and Plecoptera, University of Perugia, Perugia, Italy, 403-406.

Sartori M., Derleth P. and Webb J.M., 2007. The nymph of Atopopus tarsalis Eaton, 1881 (Ephemeroptera, Heptageniidae): first description, ecology and behaviour. Zootaxa, 1586, 25-32.

Sartori M., Peters J.G. and Hubbard M.D., 2008. A revision of Oriental Teloganodidae (Insecta, Ephemeroptera, Ephemerelloidea). Zootaxa, 1957, 1-51.

Staniczek A.H., 2010. Distribution of accessory gills in mayfly larvae (Insecta: Ephemeroptera: Siphlonuroidea, Eusetisura). Stutt. Beitr. Naturk. A, Neue Serie, 3, 85-102.

Thomas A., 1992. Gratia sororculaenadinae n.gen., n.sp., Ephéméroptère nouveau de Thaillande (Ephemeroptera, Baetidae). Bull. Soc. Hist. Nat. Toulouse, 128, 47-51.

Tong X. and Dudgeon D., 2000. Baetiella (Ephemeroptera, Baetidae) in Hong Kong, with description of a new species. Entomol. News, 111, 143-148.

Ubero-Pascal N. and Sartori M., 2009. Phylogeny of the genus Teloganopsis Ulmer, 1939 with a redescription of Teloganopsis media Ulmer, 1939 and the description of a new Oriental species (Ephemeroptera: Ephemerellidae). Aquat. Insects, 31, 101-124.

Ulmer G., 1939. Eintagsfliegen (Ephemeropteren) von den Sunda-Inseln. Arch. Hydrobiol., 16, 443-692.

Waltz R.D. and McCafferty W.P., 1987a. Generic revision of Cloeodes and description of two new genera (Ephemeroptera: Baetidae). Proc. Entomol. Soc. Wash., 89, 177-184.

Waltz R.D. and McCafferty W.P., 1987b. Systematics of Pseudocloeon, Acentrella, Baetiella, and Liebebiella, new genus (Ephemeroptera: Baetidae). J. N. Y. Entomol. Soc., 95, 553-568.

Webb J.M. and McCafferty W.P., 2007. A new genus and species of Heptageniidae (Ephemeroptera) from Borneo, with revisions to the classification of the Ecdyonurinae. Zootaxa, $1478,41-47$.

Zhou C.F., 2010. Accessory gills in mayflies (Ephemeroptera). Stutt. Beitr. Naturk. A, Neue Serie, 3, 79-84. 